\title{
The Relationship of Metabolic Syndrome and Body Composition in Children with Premature Adrenarche: Is It Age Related?
}

\author{
Kristen M. Williams ${ }^{a}$ Sharon E. Oberfield ${ }^{b}$ Chengchen Zhang ${ }^{c}$ \\ Donald J. McMahon ${ }^{c}$ Aviva B. Sopher ${ }^{b}$ \\ a Pediatric Endocrinology, Mount Sinai Medical Center, and ${ }^{b}$ Pediatric Endocrinology and ${ }^{\mathrm{C}}$ Medicine, \\ Columbia University Medical Center, New York, N.Y., USA
}

\section{Key Words}

Metabolic syndrome $\cdot$ Premature adrenarche $\cdot$ Body

composition · Androgen excess · Obesity

\begin{abstract}
Background: Studies that evaluate both body composition and metabolic syndrome (MeS) risk in prepubertal children with premature adrenarche (PA) are limited. Methods: Fiftyeight prepubertal children (aged 5-9 years, 33 female and 25 male), 30 with PA and 28 controls, were evaluated for the presence of MeS as defined by age-modified National Cholesterol Education Program Adult Treatment Panel III criteria. A subset had dual-energy $\mathrm{X}$-ray absorptiometry and bone markers ( $n=23 / 58$ ) to evaluate the effect of hyperandrogenism on metabolic abnormalities and body composition. $\boldsymbol{R e}$ sults: There was no difference in the prevalence of MeS between PA and controls $(p=0.138)$. Children with MeS were obese with an increased waist circumference (WC) and decreased high-density lipoprotein levels. Androgens were not associated with having more than one criterion for MeS $(p=$ 0.08 ) but were associated with triglycerides and WC ( $p=$ 0.029 and $p=0.041$, respectively). Lean mass was greater in PA subjects $(p=0.039)$, and androgens correlated with bone mineral density $(p=0.029)$ and total body fat $(p=0.008)$.
\end{abstract}

Subjects with a higher percent of body fat were more likely to have more than one MeS risk factor $(p=0.005)$. Conclusions: MeS was seen only in obese subjects whether or not they had PA. Thus, it appears that obesity drives metabolic risk in the prepubertal population rather than PA. Our findings are important in determining how the prepubertal patient with PA should be evaluated for metabolic risk.

두 2015 S. Karger AG, Base

\section{Introduction}

Adrenarche, the physiologic maturation of the adrenal gland, is defined by an increased secretion of adrenal androgen precursors that promote the development of secondary sexual hair growth and skeletal growth. Premature adrenarche (PA), the appearance of sexual hair without other pubertal signs before the age of 8 years in females and 9 years in males, reflects an increase in adrenal androgen precursor production in excess of what is considered normal for age and pubertal status [1].

Originally thought to be a benign variant of puberty, the diagnosis of PA has been associated with metabolic abnormalities including increased rates of obesity, decreased insulin sensitivity, and dyslipidemia [2-5]. Chil-

\section{KARGER 125}

(c) 2015 S. Karger AG, Base

$1663-2818 / 15 / 0846-0401 \$ 39.50 / 0$

E-Mail karger@karger.com

www.karger.com/hrp
Sharon E. Oberfield, MD

Pediatric Endocrinology, Diabetes, and Metabolism

Columbia University Medical Center

622 West 168th Street PH5E-522, New York, NY 10032 (USA)

E-Mailseo8@cumc.columbia.edu 
dren with PA have also been reported to have increased waist circumference (WC), increased waist-to-hip ratio measures, and increased total and central adipose mass compared to controls $[6,7]$. This increased central adiposity has been shown to be positively associated with fasting insulin, androgen, and lipid levels in pubertal children with PA $[6,8]$.

Overall, these findings may predict a greater risk of developing childhood metabolic syndrome (MeS). MeS is defined by abnormalities in central adiposity, glucose and lipid metabolism, and blood pressure. It has been associated with an increased incidence of type 2 diabetes mellitus and cardiovascular disease in adulthood [9], highlighting the importance of identifying risk factors earlier in life. There are few published reports of MeS and body composition assessment in children with PA $[6-8,10]$, despite the fact that an increase in fat stores is closely linked to alterations in metabolism and androgen levels. Indeed, the only report to our knowledge of MeS risk assessment in prepubertal children with PA evaluated only girls and included measures of body mass index (BMI) percentile instead of WC [10].

In this cross-sectional analysis, our primary aim was to test if prepubertal male and female children with a diagnosis of PA met criteria for childhood MeS as compared to unaffected, BMI z-score-matched controls. We further sought to address the gap in knowledge of the interaction of androgen excess, MeS, and body composition in a subset of this defined pediatric population.

\section{Methods}

Subjects

A convenience sample of 58 prepubertal girls and boys, 30 with PA and 28 controls, was evaluated. Subjects were recruited from the pediatric endocrinology practices of Columbia University Medical Center, from affiliated general pediatric practices, and in response to flyers in the community. Control subjects that were recruited from the pediatric endocrine practices were initially evaluated for excess weight gain and did not have any known endocrinopathy. Inclusion criteria for subjects with PA included the presence of pubic hair and/or axillary hair before 8 years of age in girls and 9 years in boys, the absence of true puberty (Tanner I breast stage in girls and testicular volume $\leq 3 \mathrm{ml}$ in boys), and dehydroepiandrosterone sulfate (DHEAS) or androstenedione (A4) levels in the Tanner II range. For the control group, subjects were included if they were prepubertal and did not have pubic or axillary hair on examination. Control subjects were further excluded if androgen levels were elevated. Subjects in both groups were excluded if they had a prior history of chronic illness, other known endocrinopathies, evidence of an adrenal enzyme defect on laboratory evaluation, or if they were taking any medications known to inter- fere with adrenal steroidogenesis or bone metabolism. Informed consent was obtained prior to any procedure from a parent or legal guardian, and assent was obtained for children $>7$ years of age. The study was approved by the Institutional Review Board of Columbia University Medical Center.

\section{Procedures}

The patients underwent a physical examination by a pediatric endocrinologist with Tanner staging of puberty. The anthropometric measures obtained included height, weight, WC, and blood pressure (average of 3 measures of the right arm while sitting). Early-morning levels of the following were obtained after an overnight fast: DHEAS, A4, 17-hydroxyprogesterone, glucose, insulin, luteinizing hormone, follicle-stimulating hormone, testosterone, estradiol (in girls only), and a lipid panel. Serum samples were frozen and stored at $-30^{\circ} \mathrm{C}$ until assayed. HOMA-IR was calculated as a measure of insulin resistance. A subset of patients (15 with PA and 8 controls) underwent further analysis for assessment of body composition. Whole-body dual-energy X-ray absorptiometry (DXA) for body fat and of the lumbar spine, hip, and forearm for bone mineral content were obtained at the Body Composition Unit of Columbia University Medical Center and read by a certified densitometrist in the Division of Pediatric Endocrinology. For those who underwent DXA, metabolic bone markers including 25-hydroxy-vitamin D [25(OH)D], osteocalcin (OC), and C-telopeptide levels were also obtained.

\section{Definition of $M e S$}

Subjects were classified as having childhood MeS, as defined by the 2003 Cook et al. [9] age-modified Adult Treatment Panel (ATP) III, if they met 3 or more of the following criteria: WC $\geq 90$ th percentile for age and sex, fasting glucose $\geq 100 \mathrm{mg} / \mathrm{dl}$, systolic blood pressure $\geq 90$ th percentile for age, sex, and height, high-density lipoprotein (HDL) $\leq 40 \mathrm{mg} / \mathrm{dl}$, and triglyceride (TG) levels $\geq 110 \mathrm{mg} / \mathrm{dl}$.

\section{Assays}

Assays of insulin, luteinizing hormone, and follicle-stimulating hormone were performed via chemiluminescence, and assays of DHEAS, A4, 17-hydroxyprogesterone, total testosterone, and estradiol were performed by high-performance liquid chromatography/tandem mass spectrometry (HPLC-MS) by Esoterix Laboratory Services (Esoterix, Inc., Calabasas Hills, Calif., USA). Serum glucose and the lipid panel were analyzed by colorimetry, C-telopeptide and OC levels were analyzed by ELISA, and 25(OH)D by LC-MS/MS at the Biomarkers Core Laboratory of the Irving Institute for Clinical and Translational Research (Columbia University, New York, N.Y., USA).

\section{Body Composition}

Whole-body DXA scans were obtained using Lunar DPX/ DPXL models with pediatric software version 3.8G (GE Healthcare, Madison, Wisc., USA) to give measures of fat-free and fat mass in kilograms, percent of body fat, total content in grams, and total body bone mineral density (BMD) in grams per $\mathrm{cm}^{2}$. Quality control was maintained by employing an anthropometric spine phantom made of calcium hydroxyapatite embedded in a Lucite block prior to scanning of every subject. Ethanol and water bottles, simulating fat and fat-free tissues, were scanned for soft-tissue markers every month. 
Statistical Analysis

All statistical analyses were performed using the SAS software (version 9.4, SAS Institute, Cary, N.C., USA). Continuous data are reported as means \pm standard deviations. Categorical data are reported as frequencies and percentages. Differences between groups were analyzed via one-way ANOVA. The $\chi^{2}$ test was used to assess the differences between categorical data. Pearson's correlation was used to assess relationships between androgen levels and other parameters. Multinomial logistic regression was used to assess relationships between $\mathrm{MeS}$ risk and other continuous variables. A p value of $<0.05$ was considered statistically significant.

\section{Results}

There was no significant difference in the distribution of age $(p=0.299)$, sex $(p=0.120)$, height $(p=0.117)$, or BMI $z$-score $(\mathrm{p}=0.145)$ between the PA and control groups (table 1). Six subjects, all in the PA group, were classified as small for gestational age; $15 / 30$ (50\%) children with PA and 20/28 (71.4\%) controls were classified as obese (BMI $>95 \%$ for age and sex). Androgen levels including DHEAS and A4, as expected, were significantly higher in PA subjects $(\mathrm{p}<0.0001)$.

\section{Analysis for $\mathrm{MeS}$}

Thirty percent of children with PA and $50 \%$ of the control group had a WC $>90$ th percentile for age, sex, and ethnicity [11]; however, this difference did not attain statistical significance $(p=0.263)$. Systolic blood pressure was lower in the PA group compared to controls $(\mathrm{p}=$ 0.019 ), and $3 \%$ of PA and $25 \%$ of control children had a systolic blood pressure $>90$ th percentile for age, sex, and height $(\mathrm{p}=0.016)$.

Average TG levels were significantly lower in the PA group as compared to controls ( $\mathrm{p}=0.034)$; however, only 2 children with PA (6.67\%) and 4 children in the control group $(14.3 \%)$ had levels $>110 \mathrm{mg} / \mathrm{dl}(\mathrm{p}=0.341)$. There was no significant difference in average fasting glucose $(\mathrm{p}=0.103)$ or in the percent of patients with glucose levels $>100 \mathrm{mg} / \mathrm{dl}(\mathrm{p}=0.103)$. There was also no significant difference in HDL levels between the groups $(\mathrm{p}=0.388)$.

Of the 5 children overall $(8.6 \%)$ that met the criteria for MeS, 1 was classified as having PA (3.3\% of the PA group) and 4 were in the control group (14.2\%). The difference in the frequency of MeS was not significantly different between the groups ( $\mathrm{p}=0.138)$, and these findings did not change with the exclusion of those classified as small for gestational age. All 5 children with MeS had a WC $>90$ th percentile for age, sex, and ethnicity, all were classified as obese, and 4/5 (80\%) had HDL levels $<40 \mathrm{mg} /$
Table 1. Patient baseline anthropometric, hormonal, and metabolic characteristics

\begin{tabular}{lccc}
\hline & $\begin{array}{l}\text { PA } \\
(\mathrm{n}=30)\end{array}$ & $\begin{array}{l}\text { Controls } \\
(\mathrm{n}=28)\end{array}$ & p value \\
\hline Age, years & $8.05 \pm 1.27$ & $7.05 \pm 0.99$ & 0.299 \\
Sex, male/female & $10 / 20$ & $15 / 13$ & 0.120 \\
BMI & $19.57 \pm 3.98$ & $21.6 \pm 5.21$ & 0.164 \\
BMI z-score & $1.05 \pm 1.11$ & $1.51 \pm 1.28$ & 0.145 \\
Obese, \% & 50 & 71.4 & 0.096 \\
DHEAS, $\mu$ g/dl & $65.03 \pm 50.72$ & $21.14 \pm 18.36$ & $<0.001^{*}$ \\
A4, ng/dl & $46.69 \pm 16.26$ & $27 \pm 8.63$ & $<0.001^{*}$ \\
WC, cm & $63.89 \pm 10.51$ & $67.46 \pm 13.53$ & 0.263 \\
WC $>90$ th percentile, \% & 30 & 50 & 0.198 \\
HDL, mg/dl & $55.07 \pm 12.96$ & $51.12 \pm 12.70$ & 0.388 \\
HDL $£ 40$ mg/dl, \% & 10 & 14.3 & 0.616 \\
SBP, mm Hg & $94.4 \pm 10.35$ & $102.77 \pm 11.61$ & $0.019^{*}$ \\
SBP ${ }^{3}$ 90th percentile, \% & 3.33 & 25 & $0.016^{*}$ \\
TG, mg/dl & $63.63 \pm 21.65$ & $83.31 \pm 43.15$ & $0.034^{*}$ \\
TG ${ }^{3} 110$ mg/dl, \% & 6.67 & 14.3 & 0.341 \\
FG, mg/dl & $87.33 \pm 7.88$ & $90.75 \pm 7.78$ & 0.103 \\
FG ${ }^{3} 100$ mg/dl, \% & 10 & 14.3 & 0.616 \\
MeS, \% & 3.33 & 14.28 & 0.138 \\
HOMA-IR & $1.47 \pm 1.11$ & $1.53 \pm 1.37$ & 0.857 \\
\hline
\end{tabular}

Values are means \pm standard deviations unless otherwise specified. $\mathrm{SBP}=$ Systolic blood pressure; FG = fasting glucose . * Statistically significant $\mathrm{p}$ values.

dl. The likelihood of having more than one criterion for $\mathrm{MeS}$ was not increased with increasing levels of A4 [odds ratio (OR) 1.039, 95\% confidence interval (CI) 0.995 1.085] or of DHEAS (OR 1.01, 95\% CI 0.994-1.027). Further, there was no significant difference in insulin resistance as measured by HOMA-IR between the groups $(\mathrm{p}=0.857)$.

\section{Body Composition Assessment}

Twenty-three of the 58 subjects who underwent metabolic evaluation (15 with PA, 8 controls) also underwent DXA and a metabolic bone workup which included bone turnover markers and 25(OH)D levels (table 2).

For this subset of PA and control children, there was no significant difference in age or BMI z-score. There was no significant difference in WC $(\mathrm{p}=0.535)$ or in the percent meeting criteria for MeS $(\mathrm{p}=0.455)$. Twelve of 23 (52\%) children were positive for at least one MeS risk factor, and only 1 female child with PA who was obese met criteria for MeS. In the PA group, TG levels and WC were both found to be positively associated with increasing A4 levels ( $\mathrm{p}=0.029$ and $\mathrm{p}=0.041$, respectively). 
Table 2. Body composition in a subset of 23 out of 58 patients

\begin{tabular}{lccc}
\hline & $\begin{array}{l}\text { PA } \\
(\mathrm{n}=15)\end{array}$ & $\begin{array}{l}\text { Controls } \\
(\mathrm{n}=8)\end{array}$ & p value \\
\hline Age, years & $7.44 \pm 1.40$ & $6.93 \pm 1.24$ & 0.400 \\
Sex, male/female & $3 / 12$ & $7 / 1$ & $0.002^{*}$ \\
BMI & $20 \pm 3.96$ & $18.49 \pm 2.28$ & 0.208 \\
BMI z-score & $1.32 \pm 0.95$ & $0.99 \pm 1.07$ & 0.451 \\
Obese, \% & 53.33 & 50 & 0.879 \\
DHEAS, $\mu$ g/dl & $66.2 \pm 53.01$ & $12.88 \pm 5.84$ & $0.001^{*}$ \\
A4, ng/dl & $47.93 \pm 18.34$ & $23.5 \pm 10.51$ & $0.002^{*}$ \\
WC, cm & $63.07 \pm 9.53$ & $60.63 \pm 7.30$ & 0.535 \\
WC $>$ 90th percentile, \% & 33.3 & 37.5 & 0.842 \\
HOMA-IR & $1.71 \pm 1.32$ & $1.14 \pm 1.25$ & 0.319 \\
MeS, \% & 6.67 & 0 & 0.455 \\
Total body BMD, g/cm ${ }^{2}$ & $0.87 \pm 0.05$ & $0.85 \pm 0.05$ & 0.319 \\
Lean mass, g & $20,187.67 \pm 3,903.49$ & $17,501 \pm 1,942.6$ & $0.039^{*}$ \\
Total fat, g & $10,421.2 \pm 6,613.2$ & $7,695.9 \pm 4,334.3$ & 0.305 \\
Percent body fat, \% & $30.99 \pm 11.43$ & $28.85 \pm 11.02$ & 0.672 \\
Osteocalcin, ng/ml & $41.04 \pm 16.83$ & $40.39 \pm 6.76$ & 0.897 \\
C-telopeptide, ng/ml & $0.485 \pm 0.322$ & $0.535 \pm 0.695$ & 0.852 \\
25(OH)D, ng/ml & $22.89 \pm 10.39$ & $28.09 \pm 8.13$ & 0.232 \\
\hline
\end{tabular}

Values are means \pm standard deviations unless otherwise specified. * Statistically significant $\mathrm{p}$ values.
With respect to body composition, lean mass was significantly greater in the PA group ( $\mathrm{p}=0.039)$; however, there was no significant difference in total body BMD $(\mathrm{p}=0.319)$, total fat, or percent of body fat between the PA and control groups as a whole. OC, C-telopeptide, and 25(OH)D levels were similar for both groups.

In PA subjects, DHEAS was positively correlated with $\mathrm{BMD}(\mathrm{r}=0.5603, \mathrm{p}=0.0298)$, lean mass $(\mathrm{r}=0.7075, \mathrm{p}=$ $0.0032)$, and total body fat $(r=0.6528, p=0.0083)$. Subjects with a higher total body fat and percent of body fat were more likely to have more than one MeS risk factor ( $\mathrm{p}=0.0106$ and $\mathrm{p}=0.0051$, respectively). This association was not seen between total body BMD $(\mathrm{p}=0.3384)$ or lean mass $(\mathrm{p}=0.7008)$ and MeS risk factors. While there existed a trend of increasing OC levels and increasing DHEAS levels with increased likelihood of more MeS criteria, this did not reach statistical significance $(\mathrm{p}=0.08$ and $\mathrm{p}=0.08$, respectively).

\section{Discussion}

To our knowledge, this is the first study reporting on both male and female prepubertal children with PA, as compared to BMI z-score-comparable controls, that evaluates the risk of $\mathrm{MeS}$ along with its effects on body com- position. Studies of both prepubertal and pubertal children suggest that, in some children, PA may not be a benign variant of normal development. Increased levels of androgens and their precursors have been linked to an increased risk of obesity, insulin resistance $[2-4,12]$ and diabetes mellitus, an adverse lipid profile [13], and cardiovascular disease [2,14-16]. Elevated androgen levels are also associated with an increase in central adiposity $[16,17]$. The androgen-mediated effects on bone, however, may be protective [18-20]. Therefore, we sought to determine competing factors on MeS risk and body composition in children with early-onset androgen excess.

$\mathrm{MeS}$ represents a constellation of cardiovascular disease risk factors [21, 22]. Modified criteria for MeS have been established in children $[9,23,24]$. With the knowledge that none of the definitions for MeS have been validated for children under 10 years of age [25], we chose to apply the ATP III age-modified Cook et al. [9] definition to our population as the inclusion of WC best represented a measure of central adiposity and may predict an increased risk of cardiovascular disease [26].

The data that we have reported demonstrate that there is no increase in the prevalence of childhood MeS in prepubertal girls and boys with PA. This is in contrast to prior studies $[10,12]$ where children with signs of PA had an increased risk compared to controls. Utriainen et al. [10] 
reported on $16-24 \%$ of PA females who met criteria for $\mathrm{MeS}$ compared to $5-10 \%$ of controls. In contrast to our study, the control group was not matched for BMI z-score. Additionally, in our study, only obese subjects were more likely to have MeS. Of the 5 subjects who met criteria for $\mathrm{MeS}$ in this report (both PA and control), all were classified as obese and also had increased WC measures, indicating that adrenarche status alone may not be enough to contribute to an altered metabolic profile at this young age.

There are conflicting reports in the literature with respect to dyslipidemia in PA [10, 27-29]. In our sample, the PA and control groups did not vary significantly in HDL levels which were mostly normal for age. This is in accord with prior studies involving a population comprising similar ethnic backgrounds [30]. Low HDL and elevated total cholesterol levels have been described in PA children; however, adverse lipid profiles were seen with advancing age [31], providing an explanation for the absence of overt dyslipidemia in our prepubertal subjects. Four out of the 5 children with MeS in this study did have HDL levels $<40 \mathrm{mg} / \mathrm{dl}$, which may confer an increased risk for cardiovascular disease in the future [32]. Interestingly, the PA group had lower TG levels than controls. Elevated TG levels in children with a history of premature pubarche and insulin resistance have been reported [27], but other studies have found significantly lower TG levels in children with PA [33]. Furthermore, lower TG levels were described in adult females with polycystic ovary syndrome [34]. In those women who had elevations in DHEAS alone, a protective effect on TG levels was found, even when compared to the healthy reference group. Also of note in our study, systolic blood pressure was significantly higher in the control group. This is possibly due to a larger number of obese controls, particularly a subset that had significantly higher blood pressure measurements. We also sought to assess if the number of positive $\mathrm{MeS}$ risk factors was associated with androgen levels. While DHEAS and A4 levels did not correlate with the number of MeS risk factors, both were positively associated with specific components of MeS, specifically an increased WC.

We performed a further analysis on a subset of both PA and control subjects to evaluate body composition in the setting of androgen excess and metabolic dysregulation. The skeleton is now recognized as an important part of energy homeostasis, specifically with respect to fat and glucose metabolism [35]. Androgen-mediated effects lead to a net increase in bone density by increasing bone mineralization via osteoblast differentiation, as well as by decreasing bone turnover [20]. Utriainen et al. [7] have re-

Metabolic Syndrome, Body Composition and Premature Adrenarche ported an increased BMD in prepubertal children with PA; however, this finding did not persist after adjusting for height. Even when adjusted for age, weight, height, and fat mass, Sopher et al. [36] did find an increase in wholebody BMD in prepubertal females with PA. In our population, while DHEAS levels were positively associated with BMD, we did not find a statistical difference in total body BMD between PA children and controls. This may be a result of the small sample size as only 23 patients had DXA and bone markers available for analysis. Furthermore, the duration of exposure to an androgen effect may be relatively limited in this young age group as patients were evaluated at one point in time and, therefore, a difference between those with androgen excess and those without may not be apparent until an older age $[18,20]$, assuming there is sustained elevation in androgen levels.

Children with PA have also been found to have increased fat mass $[6,7]$. Increased central adiposity has been positively associated with androgen levels in these children [6] and with increased cardiovascular disease risk in adults [37]. Although androgen levels were also associated with total body fat, overall fat mass did not differ between groups. Despite this, we did find that with increasing total body fat, subjects were more likely to meet criteria for more than one MeS risk factor. In addition, non-bone lean mass was significantly increased in PA children as compared to controls and was also positively associated with DHEAS levels.

Finally, there was no difference in $25(\mathrm{OH}) \mathrm{D}$ levels or bone markers between the groups. OC, a protein produced by osteoblasts, is used as a marker of bone formation [38], and its production is positively influenced by androgens [20]. On a metabolic level, OC promotes insulin production and influences glucose metabolism via fat stores [39], further supporting the link between bone and metabolic health [40]. OC levels have been found to be inversely related to fat mass, BMI [41], and HOMA-IR [42] in postmenopausal women and women with polycystic ovary syndrome. Some reports have also documented an inverse relationship with MeS risk [40, 42], and adults with type 2 diabetes mellitus have significantly lower OC levels compared to their peers who do not have impaired glucose metabolism [40]. Recently, an evaluation of a large group of healthy adolescents reported a significant negative correlation between OC levels and measures of adiposity and insulin resistance [43]. In pediatric patients with androgen excess, there are no clearly defined associations between androgen levels, OC levels, and BMD scores [44]. We did not find a significant relationship between OC levels and the likelihood of hav- 
ing any MeS risk factors, which may have been a result of our smaller sample size. Further, as OC is specifically linked to insulin secretion and sensitivity and our subjects, on average, had no evidence of impaired glucose metabolism, it was not unexpected that levels did not differ between groups in this young population.

Limitations of this study include: (1) the use of a smaller subset of patients for body composition analysis; (2) the use of the Cook et al. [9] ATP III criteria for MeS for this prepubertal group (at this time, there is no consensus on which published criteria defining MeS should be used in children; as the standardized cutoffs used have only been validated in children older than 10 years, they may not be suitable for this reported group), and (3) the study design does not allow us to comment on the causal relationship between androgen levels, metabolic dysregulation, and body composition, which may have contributed to the lack of statistically significant changes in markers for MeS. Our results do, however, provide insight into the overall metabolic health of this young population.

\section{Conclusions}

We conclude that while an increased prevalence of MeS was not seen in prepubertal children with PA as compared to controls, it is important to note that none of the children with a normal BMI percentile in either the PA or control group were diagnosed with childhood MeS. We did find that those patients with increasing adiposity were more likely to have these cardiovascular risk factors. Our findings may have clinical significance with respect to how, and at what age, the clinician approaches the prepubertal patient with PA. Clearly, in those who are obese, this evaluation would allow for early intervention. Further studies are still needed to assess which factors may contribute to an increased $\mathrm{MeS}$ risk in pediatric patients with a history of PA and which children will progress to having $\mathrm{MeS}$ in adulthood.

\section{Acknowledgements}

We would like to thank all patients and their families who participated and Dr. Serge Cremers, Director of the Biomarker Core Laboratory of the Irving Institute for Clinical and Translational Research. This publication was supported by a National Institutes of Health (NIH) and National Institute of Diabetes and Digestive and Kidney Diseases T32DK06552 grant in Pediatric Endocrinology (S.E. Oberfield) and by the National Center for Advancing Translational Sciences, National Institutes of Health, through grant numbers UL1 TR000040 and KL2 TR000081. The content is solely the responsibility of the authors and does not necessarily represent the official views of the NIH. The funding organization had no role in the study design, in the collection, analysis, and interpretation of data, or in the preparation, review, and submission of the manuscript.

\section{Disclosure Statement}

The authors have nothing to disclose. The authors have no known or perceived conflicts of interest.

\section{References}

$>1$ Ibáñez L, Dimartino-Nardi J, Potau N, Saenger P: Premature adrenarche - normal variant or forerunner of adult disease? Endocr Rev 2000;21:671-696.

-2 Idkowiak J, Lavery GG, Dhir V, Barrett TG, Stewart PM, Krone N, Arlt W: Premature adrenarche: novel lessons from early onset androgen excess. Eur J Endocrinol 2011;165: 189-207.

$\checkmark 3$ Oppenheimer E, Linder B, DiMartino-Nardi $\mathrm{J}$ : Decreased insulin sensitivity in prepubertal girls with premature adrenarche and acanthosis nigricans. J Clin Endocrinol Metab 1995; 80:614-618.

-4 Uçar A, Saka N, Baş F, Bundak R, Günöz H, Darendeliler F: Precocious adrenarche in children born appropriate for gestational age: is there a difference between genders? Eur J Pediatr 2012;171:1661-1666.

$\checkmark 5$ Oberfield SE, Sopher AB, Gerken AT: Approach to the girl with early onset of pubic hair. J Clin Endocrinol Metab 2011;96:1610 1622.

-6 Ibáñez L, Ong K, de Zegher F, Marcos MV, del Rio L, Dunger DB: Fat distribution in nonobese girls with and without precocious pubarche: central adiposity related to insulinaemia and androgenaemia from prepuberty to postmenarche. Clin Endocrinol 2003;58: 372-379.

7 Utriainen P, Jääskeläinen J, Saarinen A, Vanninen E, Mäkitie O, Voutilainen R: Body composition and bone mineral density in children with premature adrenarche and the association of LRP5 gene polymorphisms with bone mineral density. J Clin Endocrinol Metab 2009;94:4144-4151.

$>8$ Mathew RP, Byrne DW, Linton MF, Vaughan DE, Fazio S, Russell WE: Evidence of metabolic syndrome in lean children with premature pubarche at diagnosis. Metabolism 2008; 57:733-740.
-9 Cook S, Weitzman M, Auinger P, Nguyen M, Dietz WH: Prevalence of a metabolic syndrome phenotype in adolescents: findings from the third National Health and Nutrition Examination Survey, 1988-1994. Arch Pediatr Adolesc Med 2003;157:821-827.

-10 Utriainen P, Jääskeläinen J, Romppanen J, Voutilainen R: Childhood metabolic syndrome and its components in premature adrenarche. J Clin Endocrinol Metab 2007;92:4282-4285.

-11 Fernández JR, Redden DT, Pietrobelli A, Allison DB: Waist circumference percentiles in nationally representative samples of AfricanAmerican, European-American, and Mexican-American children and adolescents. J Pediatr 2004; 145:439-444.

12 Hart R, Doherty DA, Mori T, Huang RC, Norman RJ, Franks S, Sloboda D, Beilin L, Hickey $\mathrm{M}$ : Extent of metabolic risk in adolescent girls with features of polycystic ovary syndrome. Fertil Steril 2011;95:2347-2353, 53.e1. 
13 Huang R, Zheng J, Li S, Tao T, Ma J, Liu W: Characteristics and contributions of hyperandrogenism to insulin resistance and other metabolic profiles in polycystic ovary syndrome. Acta Obstet Gynecol Scand 2015;94: 494-500.

14 Conway G, Dewailly D, Diamanti-Kandarakis E, Escobar-Morreale HF, Franks S, Gambineri A, Kelestimur F, Macut D, Micic D, Pasquali R, Pfeifer M, Pignatelli D, Pugeat M, Yildiz BO; ESE PCOS Special Interest Group: The polycystic ovary syndrome: a position statement from the European Society of Endocrinology. Eur J Endocrinol 2014;171:P1P29.

$\checkmark 15$ Williams RM, Ward CE, Hughes IA: Premature adrenarche. Arch Dis Child 2012;97: 250-254.

-16 Spritzer PM, Lecke SB, Satler F, Morsch DM: Adipose tissue dysfunction, adipokines, and low-grade chronic inflammation in polycystic ovary syndrome. Reproduction 2015; 149:R219-R227.

$\checkmark 17$ Villa J, Pratley RE: Adipose tissue dysfunction in polycystic ovary syndrome. Curr Diab Rep 2011;11:179-184.

- 18 To WW, Wong M: A comparison of bone mineral density in oligomenorrhoeic adolescents with polycystic ovaries and normal ovaries. Gynecol Endocrinol 2005;20:237-242.

-19 Di Carlo C, Shoham Z, MacDougall J, Patel A, Hall ML, Jacobs HS: Polycystic ovaries as a relative protective factor for bone mineral loss in young women with amenorrhea. Fertil Steril 1992;57:314-319.

20 Notelovitz M: Androgen effects on bone and muscle. Fertil Steril 2002;77(suppl 4):S34S41.

-21 National Cholesterol Education Program (NCEP) Expert Panel on Detection, Evaluation, and Treatment of High Blood Cholesterol in Adults (Adult Treatment Panel III): Third Report of the National Cholesterol Education Program (NCEP) Expert Panel on Detection, Evaluation, and Treatment of High Blood Cholesterol in Adults (Adult Treatment Panel III) final report. Circulation 2002;106:3143-3421.

-22 Alberti KG, Zimmet PZ: Definition, diagnosis and classification of diabetes mellitus and its complications. Part 1: diagnosis and classification of diabetes mellitus provisional report of a WHO consultation. Diabet Med 1998;15: 539-553.

23 de Ferranti SD, Gauvreau K, Ludwig DS, Neufeld EJ, Newburger JW, Rifai N: Prevalence of the metabolic syndrome in American adolescents: findings from the Third National Health and Nutrition Examination Survey. Circulation 2004;110:2494-2497.

Metabolic Syndrome, Body Composition and Premature Adrenarche
24 Andersen LB, Lauersen JB, Brønd JC, Anderssen SA, Sardinha LB, Steene-Johannessen J, McMurray RG, Barros MV, Kriemler S, Møller NC, Bugge A, Kristensen PL, RiedLarsen M, Grøntved A, Ekelund U: A new approach to define and diagnose cardiometabolic disorder in children. J Diabetes Res 2015;2015:539835.

25 Zimmet P, Alberti KG, Kaufman F, Tajima N, Silink M, Arslanian S, Wong G, Bennett P, Shaw J, Caprio S; IDF Consensus Group: The metabolic syndrome in children and adolescents - an IDF consensus report. Pediatr Diabetes 2007;8:299-306.

26 Gishti O, Gaillard R, Durmus B, Abrahamse $M$, van der Beek EM, Hofman A, Franco OH, de Jonge LL, Jaddoe VW: BMI, total and abdominal fat distribution, and cardiovascular risk factors in school-age children. Pediatr Res 2015;77:710-718.

27 Ibáñez L, Potau N, Chacon P, Pascual C, Carrascosa A: Hyperinsulinaemia, dyslipaemia and cardiovascular risk in girls with a history of premature pubarche. Diabetologia 1998;41:1057-1063.

28 Güven A, Cinaz P, Bideci A: Is premature adrenarche a risk factor for atherogenesis? Pediatr Int 2005;47:20-25.

29 Livadas S, Dracopoulou M, Vasileiadi K, Lazaropoulou C, Magiakou MA, Xekouki P, Voutektakis A, Kanaka-Gantenbein C, Papassotiriou I, Stefanadis C, Chrousos GP, Dacou-Voutetakis C: Elevated coagulation and inflammatory markers in adolescents with a history of premature adrenarche. Metabolism 2009;58:576-581.

30 Jean AM, Hassoun A, Hughes J, Pomeranz C, Fennoy I, McMahon DJ, Oberfield SE: Utility of early insulin response and proinsulin to assess insulin resistance. J Pediatr 2009;155: 893-899.

31 de Ferran K, Paiva IA, Garcia Ldos S, Gama Mde P, Guimarães MM: Isolated premature pubarche: report of anthropometric and metabolic profile of a Brazilian cohort of girls. Horm Res Paediatr 2011;75:367-373.

32 Gordon T, Castelli WP, Hjortland MC, Kannel WB, Dawber TR: High density lipoprotein as a protective factor against coronary heart disease. The Framingham Study. Am J Med 1977;62:707-714.

33 Uçar A, Saka N, Baş F, Hatipoğlu N, Bundak R, Darendeliler F: Reduced atherogenic indices in prepubertal girls with precocious adrenarche born appropriate for gestational age in relation to the conundrum of DHEAS. Endocr Connect 2013;2:1-10.

34 Lerchbaum E, Schwetz V, Giuliani A, Pieber TR, Obermayer-Pietsch B: Opposing effects of dehydroepiandrosterone sulfate and free testosterone on metabolic phenotype in women with polycystic ovary syndrome. Fertil Steril 2012;98:1318-1325.e1.
35 Abseyi N, Şıklar Z, Berberoğlu M, Hacıhamdioğlu B, Savaş Erdeve Ş, Öçal G: Relationships between osteocalcin, glucose metabolism, and adiponectin in obese children: is there crosstalk between bone tissue and glucose metabolism? J Clin Res Pediatr Endocrinol 2012;4:182-188.

36 Sopher AB, Thornton JC, Silfen ME, Manibo A, Oberfield SE, Wang J, Pierson RN, Levine LS: Prepubertal girls with premature adrenarche have greater bone mineral content and density than controls. J Clin Endocrinol Metab 2001;86:5269-5272.

- 37 Cornier MA, Després JP, Davis N, Grossniklaus DA, Klein S, Lamarche B, LopezJimenez F, Rao G, St-Onge MP, Twofighi A, Poirier P; AHA Obesity Committee of the Council on Nutrition, Physical Activity and Metabolism, Council on Arteriosclerosis, Thrombosis and Vascular Biology, Council on Cardiovascular Disease in the Young, Council on Cardiovascular Radiology and Intervention, Council on Cardiovascular Nursing, Council on Epidemiology and Prevention, Council on the Kidney in Cardiovascular Disease, and Stroke Council: Assessing adiposity: a scientific statement from the American Heart Association. Circulation 2011;124:1996-2019.

38 Zanatta LC, Boguszewski CL, Borba VZ, Kulak CA: Osteocalcin, energy and glucose metabolism. Arq Bras Endocrinol Metabol 2014; 58:444-451.

39 Fukumoto S, Martin TJ: Bone as an endocrine organ. Trends Endocrinol Metab 2009;20: 230-236.

40 Alfadda AA, Masood A, Shaik SA, Dekhil H, Goran M: Association between osteocalcin, metabolic syndrome, and cardiovascular risk factors: role of total and undercarboxylated osteocalcin in patients with type 2 diabetes. Int J Endocrinol 2013;2013:197519.

41 Jürimäe J, Lätt E, Mäestu J, Saar M, Purge P, Maasalu K, Jurimae T: Osteocalcin is inversely associated with adiposity and leptin in adolescent boys. J Pediatr Endocrinol Metab 2015;28:571-577.

42 Lee SW, Jo HH, Kim MR, Kim JH, You YO: Association between osteocalcin and metabolic syndrome in postmenopausal women. Arch Gynecol Obstet 2015;292:673-681.

43 Boucher-Berry C, Speiser PW, Carey DE, Shelov SP, Accacha S, Fennoy I, Rapaport R, Espinal Y, Rosenbaum M: Vitamin D, osteocalcin, and risk for adiposity as comorbidities in middle school children. J Bone Miner Res 2012;27:283-293.

44 Reisch N, Arlt W, Krone N: Health problems in congenital adrenal hyperplasia due to 21-hydroxylase deficiency. Horm Res Paediatr 2011;76:73-85. 